\title{
Repair of Stanford type A aortic dissection with ascending aorta and hemiarch replacement combined with stent-graft elephant trunk technique by using innominate cannulation
}

\author{
Enyi Shi, MD, PhD, Tianxiang Gu, MD, PhD, Lei Yu, MD, Zongyi Xiu, MD, Zhiwei Zhang, MD, PhD, \\ Chun Wang, MD, PhD, and Qin Fang, MD, PhD
}

\begin{abstract}
Objective: The objective was to report our experience with a simplified procedure of ascending aorta and hemiarch replacement with a stent-graft elephant trunk in type A dissections. The efficacy of innominate artery cannulation was investigated.
\end{abstract}

\begin{abstract}
Methods: From January 2007 to January 2010, 46 patients (35 men, 11 women; mean age, $52.7 \pm 12.3$ years) with acute type A dissection with 3 vessels of the arch free of lesions received ascending aorta and hemiarch replacement with implantation of a stent graft into the descending aorta under hypothermic circulatory arrest and selective antegrade cerebral perfusion. The innominate artery was used for artery cannulation.
\end{abstract}

\begin{abstract}
Results: Cardiopulmonary bypass time was $107.9 \pm 17.7$ minutes, and the time of selective antegrade cerebral perfusion was $35.5 \pm 7.1$ minutes. The in-hospital mortality was $2.2 \%$ (1/46). No permanent neurologic dysfunction and paraplegia were observed. Three patients were lost to follow-up. The average follow-up time was $13.7 \pm 7.4$ months. Three months after the operation, the false lumen of the distal aorta decreased significantly with thrombosis around the stent graft in all the patients (42/42), at the level of the middle descending aorta in $81.1 \%(37 / 42)$ of the patients, and at the diaphragmatic level in $73.8 \%(31 / 42)$ of the patients. No reoperation related to residual dissected aorta was carried out.
\end{abstract}

Conclusions: The simplified procedure of ascending aorta and hemiarch replacement with a stent-graft elephant trunk performed by using innominate artery cannulation is safe and effective in patients with acute type A dissection without involvement of 3 vessels of the arch. (J Thorac Cardiovasc Surg 2011;142:1458-63)

Acute aortic dissections of Stanford type A that conjointly affect the ascending aorta, the arch, and more distal aorta continue to challenge surgeons. Total replacement of the ascending aorta and arch combined with implantation of an elephant trunk graft into the descending aorta is recommended for type A aortic dissection by some authors. ${ }^{1,2}$ A second-stage procedure to extend the elephant trunk graft to the healthy distal aorta with a thoracotomy or thoracoabdominal approach may be necessary. ${ }^{3}$ Hypothermic circulatory arrest (HCA) with selective antegrade cerebral perfusion (SCP) is a routine approach in such a surgical procedure. ${ }^{4,5}$ The right axillary artery is a favorable choice for artery cannulation, and an extra incision beside the median sternotomy is necessary for exposure of the right axillary artery. $^{2}$ Despite the recent advances in surgical techniques, the morbidity and mortality risks associated with this complex approach remain substantial. ${ }^{1,6}$

From the Department of Cardiac Surgery, First Affiliated Hospital, China Medical University, Shenyang, China.

Disclosures: Authors have nothing to disclose with regard to commercial support. Received for publication July 29, 2010; revisions received Jan 10, 2011; accepted for publication Feb 22, 2011; available ahead of print April 1, 2011.

Address for reprints: Tianxiang Gu, MD, PhD, Professor and Chairman, Department of Cardiac Surgery First Affiliated Hospital, China Medical University, Shenyang, People's Republic of China 110001 (E-mail: cmugtx@sina.com).

0022-5223/\$36.00

Copyright (c) 2011 by The American Association for Thoracic Surgery doi:10.1016/j.jtcvs.2011.02.027
In patients with acute type A aortic dissection without affecting 3 branches of the arch, replacement of the ascending aorta and hemiarch combined with implantation of a transluminal stent graft into the descending aorta, a more simplified procedure than total arch replacement, was performed in our institute. Cardiopulmonary bypass (CPB) and SCP during HCA were performed by innominate artery cannulation. In this article, we highlighted such a simplified technique by using innominate artery cannulation for selective acute type A aortic dissections and reported the outcomes in 46 cases.

\section{PATIENTS AND METHODS}

From January 2007 to January 2010, 46 patients with acute type A aortic dissection with 3 branches of the arch free of lesions underwent ascending aorta and hemiarch replacement combined with stent-graft elephant trunk implantation by using innominate artery cannulation. Thirty-five patients were male and 11 patients were female, with an average age of $52.7 \pm$ 12.3 years (range, 29-73 years). The diagnosis was made by computed tomographic angiography (CTA) or magnetic resonance angiography (MRA) in all patients. Three branches of the arch were confirmed to be free of dissection on CTA or MRA. The innominate artery was also examined to exclude atherosclerosis, plaques, stenosis, and other artery lesions. The study was approved by the Ethics Committee of the First Affiliated Hospital, China Medical University. Further preoperative data are listed in Table 1.

\section{Surgical Procedure}

A median sternotomy was performed with the upper end of the incision being made higher. The innominate artery was mobilized to the bifurcation 


\section{Abbreviations and Acronyms \\ $\mathrm{CPB}=$ cardiopulmonary bypass \\ $\mathrm{CTA}=$ computed tomographic angiography \\ HCA $=$ hypothermic circulatory arrest \\ MRA = magnetic resonance angiography \\ SCP $=$ selective antegrade cerebral perfusion}

and retracted caudally. After systemic heparinization, 4-0 Prolene polypropylene (Ethicon, Inc, Somerville, NJ) double purse-string sutures were made at the innominate artery. Then the innominate artery was stabbed and a $22 \mathrm{~F}$ or $24 \mathrm{~F}$ wire-reinforced flexible short-tipped cannula was introduced with the tip pointing toward the aortic arch (Figure 1, A). ${ }^{7}$ Venous return was established with a 2 -stage cannula introduced via the right atrium. When the patient was cooled to $32^{\circ} \mathrm{C}$, the aorta was clamped just proximal to the innominate artery. After a careful inspection of the aortic valve and the coronary ostia, a decision was made about the subsequent root procedure. Supracommissural aortic replacement was performed with a suitable vessel prosthesis if the root was not involved in the dissection and no aortic insufficiency was present. If the aortic regurgitation was severe, a Bentall procedure (replacement of the aortic valve, aortic root, and ascending aorta, with reimplantation of the coronary arteries into the graft) or a Wheat procedure (replacement of the aortic valve and ascending aorta) was performed according to whether the coronary ostia were affected by the dissection. During this period, the body temperature was continually decreased. After the root procedure was accomplished, reaching the anticipated HCA rectal temperature of $25^{\circ} \mathrm{C}$, circulation was arrested. The innominate artery cannula was rotated gently with the tip toward the head, and a vascular clamp was applied proximal to the cannula (Figure 1, $B$ ). Then SCP was performed through the innominate artery cannula at a rate of 8 to $10 \mathrm{~mL} \cdot \mathrm{kg}^{-1} \cdot \mathrm{min}^{-1}$. The arch was transected obliquely. After measurement of the true lumen of descending aorta, a self-expandable stent vessel prosthesis (MicroPort Medical Co, Ltd, Shanghai, China) $2 \mathrm{~mm}$ larger than the diameter of the true lumen with a length of about 8 to 10 $\mathrm{cm}$ was inserted into the descending aorta. ${ }^{8}$ The proximal end of the stent vessel prosthesis was positioned just distal to the opening of the left subclavian artery and fixed to the aorta with a continuous suture. According to the arch incision, the distal end of the vessel prosthesis for replacement of the ascending aorta was trimmed as a suitable shape and the distal anastomosis was accomplished with a continuous suture using an open aortic technique. The surgical procedure is illustrated in Figure 2. Then the innominate artery cannula was rotated back with the tip toward the arch and $\mathrm{CPB}$ was gradually resumed. After $\mathrm{CPB}$, the cannula was withdrawn and the innominate artery was repaired by tying the double purse-string sutures. Coronary artery bypass grafting was conducted in 3 patients with coronary heart disease simultaneously.

\section{Neurologic Dysfunction Evaluation}

A permanent neurologic dysfunction was defined as stroke confirmed by conventional imaging techniques. A temporary neurologic dysfunction was defined as subtle but diffused brain injury and was classified into 5 grades, ${ }^{9}$ as shown in Table 2. Neuropsychologic evaluation was performed on each patient by a neurologist postoperatively.

\section{RESULTS}

Forty-one patients underwent selective operations and the other 5 patients underwent emergency operations. Aortic root operations were performed in 3 procedures, including supracommissural replacement in 35 patients, Bentall
TABLE 1. Demographic and preoperative data

\begin{tabular}{lcc}
\hline \multicolumn{1}{c}{ Characteristics } & N & Percent \\
\hline No. of patients & 46 & \\
Male & 35 & 76.1 \\
Female & 11 & 23.9 \\
Age & $52.7 \pm 12.3(29-73)$ & \\
Smoking history & 27 & 58.7 \\
BMI > 30 & 10 & 21.7 \\
Hypertension & 39 & 84.8 \\
Hyperlipidemia & 9 & 19.6 \\
Diabetes & 7 & 15.2 \\
Chronic renal failure & 3 & 6.5 \\
Coronary heat disease & 3 & 6.5 \\
Marfan syndrome & 9 & 19.6 \\
Aortic valve regurgitation & 11 & 23.9 \\
\hline
\end{tabular}

$B M I$, Body mass index.

procedure in 8 , and Wheat procedure in 3 . The average CPB time was $107.9 \pm 17.7$ minutes and the average HCA with SCP time was $35.5 \pm 7.1$ minutes. All patients were fully conscious about $4.5 \pm 1.8$ hours after the operation. The mean mechanical ventilation time was $23.4 \pm 8.1$ hours. Transient neurologic dysfunction occurred in $10 \mathrm{pa}-$ tients: seven with grade 1 , two with grade 2 , and one with grade 3 dysfunction. Permanent neurologic dysfunction and paraplegia did not occur in this series. Reoperations for hemostasis were performed in 2 patients 3.5 and 4 hours after the primary operations, respectively. One patient who received anticoagulant therapy with aspirin and clopidogrel for coronary heart disease died of multiple organ failure 3 days after reoperation for hemostasis. All other patients survived and were discharged $18.7 \pm 5.9$ days after the operation. There were no postoperative complications related to innominate artery cannulation. Three patients were lost to follow-up. The others were followed up for $13.7 \pm 7.4$ months (4-35 months), during which no death occurred. Three months after the operation, aortic CTA indicated that the false lumen of the distal aorta decreased significantly accompanied by thrombosis at the site covered by the stent graft in all the patients, at the level of the middle descending aorta in $88.1 \%(37 / 42)$ of patients, and at the diaphragmatic level in $73.8 \%$ (31/42) of patients, as shown in Figure 3. Obvious enlargement of the false lumen of the descending aorta was not observed compared with the preoperative imaging. No reoperation related to the residual dissected aorta was carried out. Patients resumed normal activities with antihypertension therapy after hospital discharge. The results are summarized in Table 3.

\section{DISCUSSION}

The optimal surgical strategy for acute type A dissections spans a wide range from the more conservative approaches using only replacement of the ascending aorta, with or without resection of the intimal tear, to more aggressive methods 


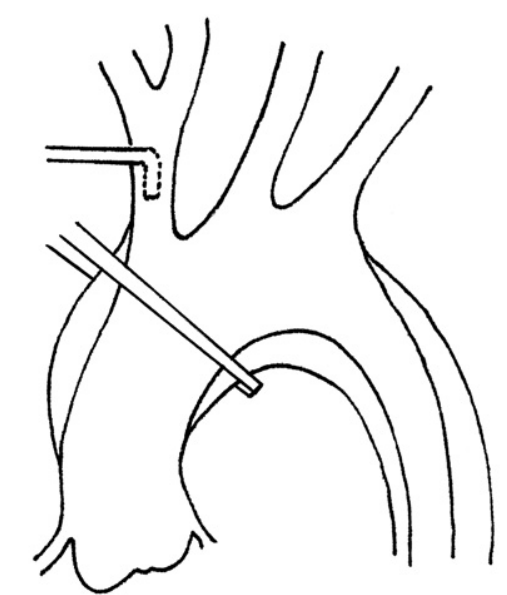

A

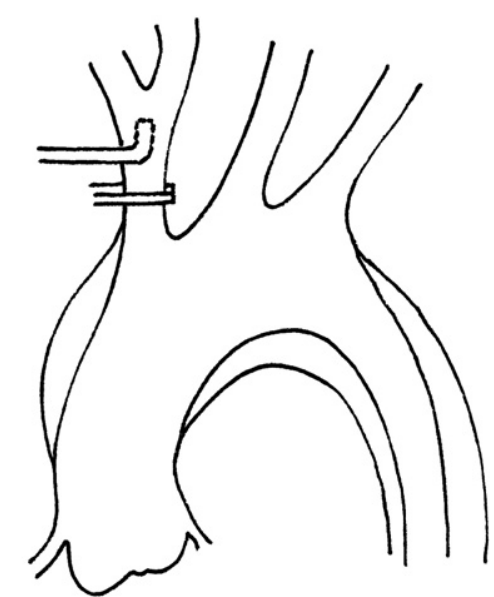

B

FIGURE 1. Diagram of innominate artery cannulation. A, For cooling and rewarming, the tip of the cannula is pointing toward the arch and the crossclamp is placed at the ascending aorta. B, For selective antegrade cerebral perfusion, the tip of the cannula is oriented toward the head and the crossclamp is placed proximal to the site of cannulation of the innominate artery.

using total replacement of the ascending aorta and aortic arch combined with elephant trunk. ${ }^{1,2,10,11}$ Replacement of the ascending aorta and arch can eliminate the lesions of the ascending aorta and arch completely, whereas the elephant trunk technique can seal the tear of the distal aorta and promote thrombosis of the false lumen, which may make the secondary operation evitable in some patients. However, most surgeons do not think it is
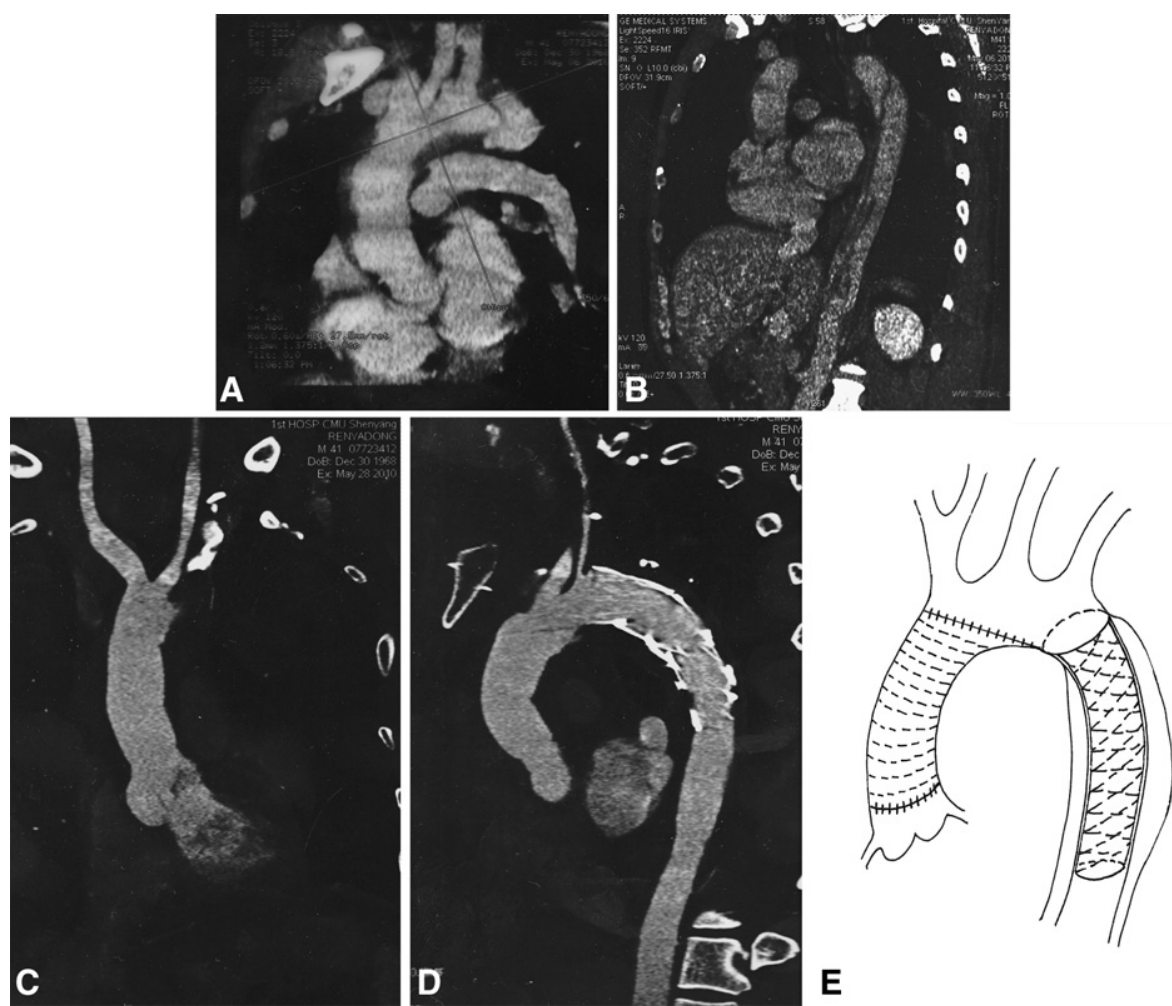

FIGURE 2. Computed tomographic angiography (CTA) and magnetic resonance angiography (MRA) of a patient with Stanford type A dissection before the operation (A and B) and 3 weeks after the operation (C and D). A, CTA shows the lesion of ascending aorta. B, MRA demonstrates the patent false lumen in the descending aorta clearly. C, CTA shows the vascular prosthesis of the ascending aorta and innominate artery. No evidence of stenosis of the innominate artery can be observed after cannulation; D, CTA shows that the stent graft is implanted in the distal aorta and the false lumen of the descending aorta is closed completely. E, Diagram of simplified stent-graft elephant trunk technique. 
TABLE 2. Clinical scale for temporary neurologic dysfunction

\begin{tabular}{cll}
\hline Grade & \multicolumn{1}{c}{ Features } & \multicolumn{1}{c}{ Duration } \\
\hline Grade 1 & Simple confusion & Short $(<48 \mathrm{~h})$ \\
Grade 2 & Confusion + lethargy & Short \\
Grade 3 & Confusion + agitation & Short $(<72 \mathrm{~h})$ \\
Grade 4 & Overt psychosis & Long $(>72 \mathrm{~h})$ \\
Grade 5 & Psychosis, parkinsonism & Long \\
\hline
\end{tabular}

necessary to replace the aortic arch for type A dissection and only a small minority does so. Complete resection of the intimal tear and redirection of flow into the true lumen are the primary objectives of surgery, which also can be achieved by simplified methods without total arch replacement. A simplified procedure of ascending aorta and hemiarch replacement combined with implantation of a transluminal stent graft into the descending aorta was preferred for patients with acute type A aortic dissections without involvement of 3 branches of the arch in our institute. The in-hospital mortality in our series was $2.2 \%$, which was lower than that of the aggressive approach of total arch replacement reported in the literature. $1,2,3,6$ Conservative methods were also demonstrated to provide consistently low mortality for acute type A dissection by other surgeons. ${ }^{10,11}$ Although the follow-up time was not very long, the short-term outcome of the current series was encouraging in that no reoperation related to the residual false lumen was carried out during a mean follow-up of $13.7 \pm 7.4$ months. In a report by Sun and associates ${ }^{2}$ of 107 patients undergoing total arch replacement with implantation of a stent graft, reoperation was unnecessary during a follow-up of $35 \pm 14$ months. Compared with the aggressive approach of total arch replacement combined with the elephant trunk technique using a conventional graft or stent graft, our simplified procedure was much easier. The time of operation, CPB, crossclamping, HCA, and SCP were significantly shortened, and the body temperature for HCA could be kept at a comparatively higher level, which may contribute to the low mortality in our group. Of course, it cannot be ignored that patients with dissection involving 3 vessels of the arch were not enrolled in the current study and the mean age of our series seemed to be younger. In our institute, the indications for the simplified procedure are strict: (1) 3 branches of the arch must be unaffected by the dissection and (2) if the intimal tear originates in or extends to the arch, it should be located at the lesser curvature of the arch. If the intimal tear originates from the proximal portion of the descending aorta, it should be located at the lesser curvature side or be no less than $1.5 \mathrm{~cm}$ distal to the initial site of the left subclavian artery. The total arch is replaced with a vessel prosthesis if the intimal tear is located at the cupular part of the arch or near to the initial site of the left subclavian artery.
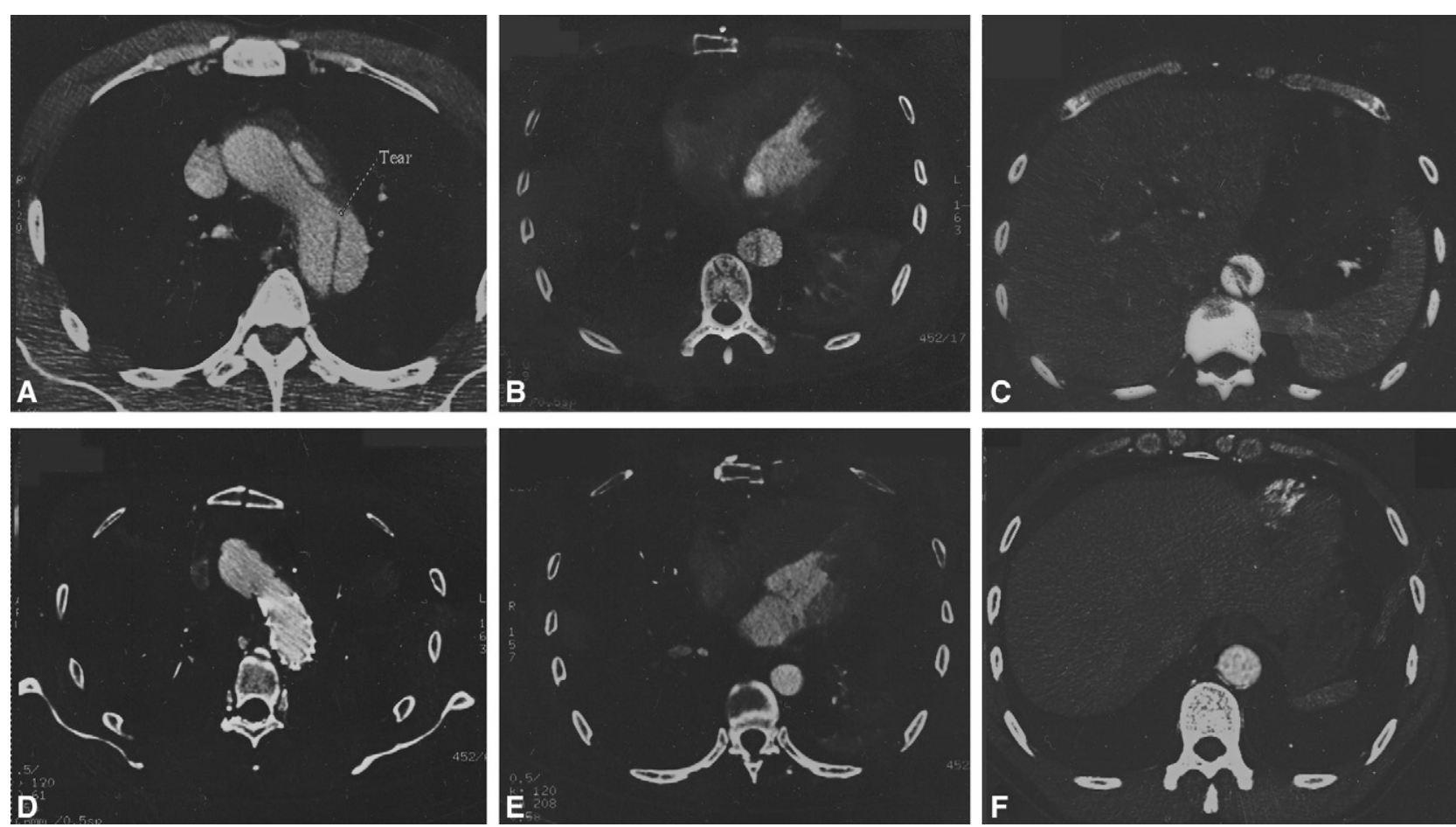

FIGURE 3. Computed tomographic angiography (CTA) of a patient with Stanford type A dissection before the operation (A, B, and C) and 1 year after the operation (D, E, and F). The patent false lumen is shown at 3 levels: proximal descending aorta (A), middle of the descending aorta (B), and diaphragmatic level (C). The true lumen in the descending aorta is restored completely and the false lumen decreases significantly by stent-graft implantation, as shown at the 3 corresponding levels $(\mathrm{C}, \mathrm{D}$, and $\mathrm{E})$. 
TABLE 3. Surgical procedure and intraoperative and postoperative data

\begin{tabular}{|c|c|c|}
\hline & $\begin{array}{c}\text { Mean } \pm \text { SD } \\
(\text { range }) / \mathbf{n}\end{array}$ & Percent \\
\hline \multicolumn{3}{|l|}{ Aortic root surgery } \\
\hline Supracommissural replacement & 35 & 76.1 \\
\hline Bentall procedure & 8 & 17.4 \\
\hline Wheat procedure & 3 & 6.5 \\
\hline CABG & 3 & 6.5 \\
\hline CPB time (min) & $107.9 \pm 17.7(75-176)$ & \\
\hline Crossclamp time (min) & $79.7 \pm 15.8(54-123)$ & \\
\hline HCA time (min) & $35.5 \pm 7.1(24-57)$ & \\
\hline SCP time (min) & $35.5 \pm 7.1(24-57)$ & \\
\hline $\begin{array}{l}\text { Lowest nasopharyngeal } \\
\text { temperature }\left({ }^{\circ} \mathrm{C}\right)\end{array}$ & $20.8 \pm 5.4$ & \\
\hline Lowest rectal temperature $\left({ }^{\circ} \mathrm{C}\right)$ & $23.7 \pm 3.7$ & \\
\hline Operative mortality & 1 & 2.2 \\
\hline Reoperation for hemostasis & 2 & 4.3 \\
\hline Mechanical ventilation time (h) & $23.4 \pm 8.1(10-127)$ & \\
\hline ICU time $(\mathrm{h})$ & $114 \pm 27(64-247)$ & \\
\hline Temporary neurologic dysfunction & 10 & 22.2 \\
\hline Grade 1 & 7 & 15.6 \\
\hline Grade 2 & 2 & 4.4 \\
\hline Grade 3 & 1 & 2.2 \\
\hline Permanent neurologic dysfunction & 0 & 0 \\
\hline Postoperative hospital stay time (d) & $18.7 \pm 5.9(11-43)$ & \\
\hline Follow-up time (mo) & $13.7 \pm 7.4(4-35)$ & \\
\hline \multicolumn{3}{|l|}{$\begin{array}{l}\text { Fate of the false lumen of the } \\
\text { descending aorta }\end{array}$} \\
\hline $\begin{array}{l}\text { Decrease with thrombosis } \\
\text { (around the stent graft) }\end{array}$ & 42 & 100 \\
\hline $\begin{array}{l}\text { Decrease with thrombosis } \\
\text { (middle descending aorta level) }\end{array}$ & 37 & 88.1 \\
\hline $\begin{array}{l}\text { Decrease with thrombosis } \\
\text { (diaphragmatic level) }\end{array}$ & 31 & 73.8 \\
\hline
\end{tabular}

$\overline{S D \text {, Standard deviation; } C A B G \text {, coronary artery bypass graft; } C P B \text {, cardiopulmonary }}$ bypass; $H C A$, hypothermia circulatory arrest; $S C P$, selective antegrade cerebral perfusion; $I C U$, intensive care unit.

A graft sustained by a self-expandable stent of the whole length except a 10-mm sewing edge at both ends was used for the elephant trunk in our series. Compared with the conventional elephant trunk, the stent can keep the graft opened fully, fix the graft to the native aortic wall, seal the tear located at the distal aorta, compress the false lumen, and effect thrombus obliteration of the downstream false channel. ${ }^{8,12}$ Inasmuch as 3 branches of the arch were reserved by our simplified procedure, the stent grafts were implanted under full exposure of the opening of left subclavian artery to avoid the possible occlusion. CTA scan after the operation showed that the left subclavian artery was partially occluded by the stent graft in 1 patient. In this patient, the arterial blood pressure of the left upper extremity was lower than that of the right side, but no other symptoms related to ischemia were observed. In our series, a stent graft $2 \mathrm{~mm}$ larger than the diameter of the true lumen of the distal aorta was selected, which may further improve the effects of sealing the intimal tear and compressing the false lumen. Three months after the operation, the false lumen of the distal aorta decreased significantly accompanied with thrombosis around the stent graft in all of the patients and distal to the stent graft in the majority of the patients. The size of the false lumen may affect the efficacy of the stent graft. If the false lumen is greater than $50 \mathrm{~mm}$ in diameter, the stent graft could hardly work. ${ }^{8,12}$

The right axillary artery is used in many centers for arterial cannulation to achieve $\mathrm{SCP}^{2,8}$ Compared with right axillary artery cannulation, innominate artery cannulation carries the following advantages. No additional incision is needed and the same technique and same size of cannula are used, as in the ascending aortic cannulation. Inasmuch as the innominate artery is usually larger than the right axillary artery, total CPB flow can be easily achieved without high pump pressures. Cerebral perfusion pressure can be monitored continuously with a right arterial line. The risk for brachial plexus injury or limb ischemia can be avoided. ${ }^{7,13}$ Innominate artery cannulation was recommended to be performed with a side graft by Huang and associates. ${ }^{14}$ This method need not adjust the tip of the cannula during the operation and can avoid the possible angiostenosis caused by tying of the purse-string sutures for direct cannulation to the innominate artery. However, extra time is needed for anastomosis of the vessel graft. Bleeding from the suture line and weeping through the graft during $\mathrm{CPB}$ are inevitable. ${ }^{14}$ In the current study, no angiostenosis related to innominate artery cannulation was observed. For type A aneurysm, innominate artery cannulation can be performed only when the innominate artery is free of dissection, atherosclerosis, stenosis, or plaques.

Regardless of the progress of surgical technique and neuroprotective measures, postoperative cerebral morbidity is still one of the serious complications after aortic arch operations. The incidence of permanent neurologic dysfunction is about $3 \%$ to $5 \%$ in patients who underwent total arch replacement. ${ }^{2,4,8}$ In the current study, no permanent neurologic dysfunction was observed. Compared with total arch replacement, the simplified procedure used in the current study shortened the SCP time, and the body temperature for HCA was controlled at a higher level, which may contribute to the decrease in postoperative cerebral complications. Another reason for such a consequence may be that the innominate artery and the left carotid artery were free of dissection in all the patients. Ischemic spinal cord injury is another critical complication after arch surgery combined with implantation of either the conventional elephant trunk or the stent-graft elephant trunk. No paraplegia was observed in our series, which may be attributed to the shortened HCA time. Also helping to avoid paraplegia, the intercostal arteries below the Th8 level were 
not occluded because stent grafts of no longer than $10 \mathrm{~cm}$ were used.

Only part of the type A dissections affects 3 branches of the arch. In our institute, a total of 65 patients with acute type A aortic dissection underwent surgical intervention in the corresponding period, and the dissections were certified to affect 3 branches of the arch in 19 patients, who received total arch replacement. Although our data may not represent the real ratio of the patients with type A dissections without involvement of 3 vessels of the arch, they still confirm that quite a few patients with acute type A aortic dissection can achieve satisfactory therapy by undergoing the simplified procedure without replacement of the total arch. Innominate artery cannulation is a simple, safe, effective, and timesaving technique to perform CPB and SCP in such a simplified procedure. The primary limitation of the current study was that comparisons between the simplified procedure group and total arch replacement with elephant trunk stent group or conventional elephant trunk group were not made. Although the preliminary outcomes of the simplified procedure by using innominate artery cannulation were encouraging, it is necessary to evaluate the long-term outcomes of this simplified procedure for acute type A aortic dissection.

\section{References}

1. Kazui T, Wasiyama N, Muhammad BA, Terada H, Yamashita K, Takinami M, et al. Extended total arch replacement for acute type A aortic dissection: experience with seventy patients. J Thorac Cardiovasc Surg. 2000;119:558-65.
2. Sun L, Qi R, Chang Q, Zhu J, Liu Y, Yu C, et al. Surgery for acute type A dissection using total arch replacement combined with stented elephant trunk implantation: experience with 107 patients. J Thorac Cardiovasc Surg. 2009;138: 1358-62.

3. Safi HJ, Miller CC III, Estrera AL, Huynh TT, Porat EE, Hassoun HT, et al. Staged repair of extensive aortic aneurysms: morbidity and mortality in the elephant trunk technique. Circulation. 2001;104:2938-42.

4. Kazui T, Washiyama N, Muhammad BA, Terada H, Yamashita K, Takinami M, et al. Total arch replacement using aortic arch branched grafts with the aid of antegrade selective cerebral perfusion. Ann Thorac Surg. 2000;70:3-8.

5. Apostolakis E, Akinosoglou K. The methodologies of hypothermic circulatory arrest and of antegrade and retrograde cerebral perfusion for aortic arch surgery. Ann Thorac Cardiovasc Surg. 2008;14:138-48.

6. Kazui T, Washiyama N, Bashar AH, Terada H, Suzuki T, Ohkura K, et al. Surgical outcome of acute type A aortic dissection: analysis of risk factors. Ann Thorac Surg. 2002;74:75-81.

7. Ji S, Yang J, Ye X, Wang X. Brain protection by using innominate artery cannulation during aortic arch surgery. Ann Thorac Surg. 2008;86:1030-2.

8. Liu ZG, Sun LZ, Chang Q, Zhu JM, Dong C, Yu CT, et al. Should the "elephant trunk" be skeletonized? Total arch replacement combined with stented elephant trunk implantation for Stanford type A aortic dissection. J Thorac Cardiovasc Surg. 2006;131:107-13.

9. Ergin MA, Uysal S, Reich DL, Apaydin A, Lansman SL, McCullough JN, et al. Temporary neurological dysfunction after deep hypothermic circulatory arrest: a clinical marker of long-term functional deficit. Ann Thorac Surg. 1999;67:1887-90.

10. Ohtsubo S, Itoh T, Takarabe K, Rikitake K, Furukawa K, Suda H, et al. Surgical results of hemiarch replacement for acute type A dissection. Ann Thorac Surg. 2002;74:S1853-6.

11. Westaby S, Saito S, Katsumata T. Acute type A dissection: conservative methods provide consistently low mortality. Ann Thorac Surg. 2002;73:707-13.

12. Mizunoa T, Toyamab M, Tabuchi N, Wu H, Sunanori M. Stented elephant trunk procedure combined with ascending aorta and arch replacement for acute type A aortic dissection. Eur J Cardiothorac Surg. 2002;22:504-9.

13. Sabik JF, Nemeh H, Lytle BW, Blackstone EH, Gillinov AM, Rajeswaran J, et al Cannulation of the axillary artery with a side graft reduces morbidity. Ann Thorac Surg. 2004;77:1315-20.

14. Huang FJ, Wu Q, Ren CW, Lai YQ, Yang S, Rui QJ, et al. Cannulation of the innominate artery with a side graft in arch surgery. Ann Thorac Surg. 2010;89:800-3. 